\title{
Role of heparinase in the gastrointestinal dysfunction of sepsis (Review)
}

\author{
TING-TING CHEN ${ }^{1}$, JIA-JUN LV ${ }^{1}$, LING CHEN ${ }^{2,3}$, YU-WEI GAO ${ }^{2,3}$ and LI-PING LIU ${ }^{2,3}$ \\ ${ }^{1}$ The First Clinical Medical School of Lanzhou University; Departments of ${ }^{2}$ Emergency Critical Care Medicine and \\ ${ }^{3}$ Emergency, The First Hospital of Lanzhou University, Lanzhou, Gansu 730000, P.R. China
}

Received May 29, 2021; Accepted October 26, 2021

DOI: $10.3892 /$ etm.2021.11042

\begin{abstract}
Heparinase (HPA) is a $\beta$-D glucuronidase that belongs to the endoglycosidase enzyme family, and plays an important role in numerous pathological and physiological processes, including inflammation, angiogenesis and tumor metastasis. When the expression of HPA is abnormally high, the side chain of heparin sulfate proteoglycans degrades, destroying the cell barrier and leading to the occurrence and development of inflammation, with systemic inflammation occurring in severe cases. Sepsis is a major cause of mortality in critically ill patients. In sepsis, the gastrointestinal tract is the first and most frequently involved target organ, which often leads to gastrointestinal dysfunction. HPA overexpression has been determined to accelerate sepsis progression and gastrointestinal dysfunction; thus, it was hypothesized that HPA may play an important role and may serve as an index for the diagnosis of gastrointestinal dysfunction in sepsis. HPA inhibitors may therefore become applicable as targeted drugs for the treatment of gastrointestinal dysfunction in patients with sepsis. The present review mainly discussed the role of HPA in gastrointestinal dysfunction of sepsis.
\end{abstract}

\section{Contents}

1. Introduction

2. HPA

3. HPA in inflammation

4. HPA in gastrointestinal dysfunction

5. HPA in sepsis

6. HPA in the gastrointestinal dysfunction of sepsis

7. Summary and perspective

Correspondence to: Dr Li-Ping Liu, Department of Emergency Critical Care Medicine, The First Hospital of Lanzhou University, 1 West Road, Chengguan, Lanzhou, Gansu 730000, P.R. China E-mail: liulipingldyy@126.com

Key words: heparinase, inflammation, sepsis, gastrointestinal dysfunction, acute gastrointestinal injury

\section{Introduction}

Heparinase (HPA) is the only enzyme in the eukaryotes that can degrade heparin (HP)/HP sulfate (HS). A search for terms such as 'heparinase', 'inflammation', 'sepsis' and 'gastrointestinal dysfunction' in electronic databases such as PubMed and Web of Science reveals that HPA has been widely used in the field of medicine. For example, HPA has been utilized to antagonize the effect of HP. HPA is mostly used in cardiopulmonary bypass surgery and can also generate low molecular weight HP (LMWH) $(1,2)$. HPA has also attracted attention due to its inflammatory effect, which destroys the cellular barrier, particularly at the basement membrane (BM), leading to gastrointestinal inflammation and dysfunction (3). Previous studies have demonstrated that HPA is closely associated with the occurrence and progression of inflammation and sepsis $(3,4)$. HPA aggravates the progression of sepsis and gastrointestinal dysfunction $(5,6)$; thus, the present review hypothesized that HPA may play an important role in the gastrointestinal dysfunction observed in sepsis. However, there are limited reports on the role of HPA in gastrointestinal dysfunction during the early stage of sepsis. Therefore, the present study mainly focused on HPA and its role in inflammation, gastrointestinal dysfunction and sepsis.

\section{HPA}

HPA is an endosaccharide nucleotide enzyme that breaks the glycosidic bond between amino sugars and uronic acids in HP, thereby degrading HP to produce disaccharides and oligosaccharides (7). HP is an important clinical drug that was identified $\sim 100$ years ago. It is a linear chain composed of 20-100 D-acetylglucosamine unsaturated units, in which D-acetylglucosamine is linked with glucuronic acid through an $\alpha-1,4$ glycosidic bond (8). HP and its structural analogue, HS, are the most complex glycosaminoglycans (GAGs), which are members of the multi-anion, multi-disperse, linear polysaccharide family (9).

HP has several important biological functions in numerous physiological and pathological processes and has been widely used in clinical treatment $(10,11)$. For example, the interaction between HP and antithrombin demonstrated that HP exerted anticoagulant effects (12). Therefore, in clinical application, HP is mainly used for the prevention and treatment of deep 
vein thrombosis and pulmonary embolism (13). In addition, LMWH is a more effective and safe anticoagulant than unfractionated heparin (UFH) due to its predictable anticoagulative response, longer half-life, lower bleeding risk and higher bioavailability (2). LMWH can also be used to treat sepsis, and there is medical evidence that LMWH can reduce the 28-day mortality rate and improve prognosis in patients with sepsis (14). Additional effects of HP, such as reducing cancer metastasis, have been previously explored and as a result, the range of its therapeutic application has increased (13).

HPA can be divided into two types according to its source: i) The HPA gene of eukaryotic origin, which expresses an enzymatic protein called eukaryotic HPA that degrades HP/HS by hydrolysis; and ii) the HPA gene of prokaryotic origin that degrades HP/HS by pyrolysis (15). Of note, all the references to HPA in the present study correspond to that of eukaryotic origin.

In 1999, the HPA gene of eukaryotic origin was purified and isolated for the first time (15). HPA is a single-copy gene that can be divided into two highly conserved subtypes: HPAI and HPA2 (16). Linear analysis of the human HPAl and HPA2 has revealed that $\sim 35 \%$ of their amino acid sequences are identical (16).

In vivo, HPA exists in lysosomes in the form of a precursor enzyme, which must be activated and modified into two active polypeptides with corresponding molecular weights of 50 and $8 \mathrm{kDa}$. These subsequently combine covalently to form a heterodimer, which finally becomes active HPA (15). In normal tissue cells, HPA is mainly distributed in the spleen, placenta, platelets, neutrophils, monocytes and activated $\mathrm{T}$ and B lymphocytes, but is not expressed in the heart, lung, brain, skeletal muscle, pancreas or kidney (15). However, HPA is commonly found in various metastatic malignant tumor cells, including lymphoma and breast, lung, stomach, liver, pancreatic, bladder, skin and colon cancer $(15,17-20)$. In addition, HPA is expressed in hyperplastic lesions, inflammation, injury, the immune response and other pathological conditions $(15,21,22)$.

HPA plays an important role in multiple physiological and pathological processes in the human body. HPA can hydrolyze the side chains of HS on heparin sulfate proteoglycans (HSPGs), destroying the basic structures of the extracellular matrix (ECM) and BM, thereby releasing and activating the active substances attached to side chains (23). HSPGs contribute to the structural integrity, self-assembly and insolubility of the ECM and BM, and are critical for regulating cell-ECM interactions (24). Numerous growth factors are bound to the side chain of HS, including hepatocyte growth factor, fibroblast growth factor and vascular endothelial growth factor (VEGF) (25). When HS is cleaved by HPA, these growth factors bind to their growth factor receptors on the cell surface and participate in intracellular signal activation, thus markedly increasing urokinase-type plasminogen activator and matrix metalloproteinase (MMP)9 levels. Upregulated MMP9 then goes on to cleave the core protein of HSPG from the cell surface, thus leading to the degradation of HSPGs (25).

A study has demonstrated that HPA induces HS-independent signal activation, which involves enhanced Akt, p38 and Src phosphorylation (26). It also causes the transcription of VEGF-A, VEGF-C, tissue factor and cyclooxygenase-2 (26). HPA promotes HSPG aggregation, which leads to a cascade of intracellular signal amplifications, as well as the activation of protein kinase C, Src and Ras-related C3 botulinum toxin substrate 1 . These activations contribute to cell adhesion and directional migration, which alters cell-cell and cell-ECM interactions (27-30). In addition, the expression of HPA in non-invasive and non-immune tissues plays an important role in tissue formation, regeneration and repair during embryonic and adult development (31). Both proenzyme and active HPA are also important for the biological function of osteoblasts, nervous system development and nerve cell differentiation (31-33).

It has been shown that HPA enhances exosmosis, and promotes the production and docking of exosomes between tumors and host cells, thus promoting tumor progression (34). HPA can promote autophagy, which when enhanced, partially mediates the HPA-induced effects of increased tumor growth and chemical resistance (35). The potential mechanism of HPA-induced autophagy is incompletely understood, but it is likely to involve mTOR1, which plays a key role in the regulation of nutrient sensing and autophagy (36). Autophagy in turn plays an important role in sepsis, the mechanism of which is relatively complex and unclear. However, it may be associated with multiple signaling pathways, including NF- $\mathrm{KB}$, mTOR and PI3K/Akt (37). Therefore, it was hypothesized that the involvement of HPA in the process of sepsis may be closely associated with autophagy, exosomes and various signaling pathways, although the specific pathways require further elucidation.

\section{HPA in inflammation}

The close association between HPA and inflammation was demonstrated $>20$ years ago. Before the HPA gene was cloned, HS degrading activity was found in various immune cells, such as neutrophils and activated T lymphocytes (38). The anti-inflammatory effects of substances that act as HPA inhibitors (such as HP) have been demonstrated (39), thus further supporting the important role of HPA in the inflammatory response.

Under normal physiological conditions, HPA levels are relatively low. The expression of HPA in normal tissues is limited to the placenta and activated immune cells (40). However, when physiological homeostasis is disrupted, in situations such as cancer, inflammation and thrombosis, the expression of HPA is increased and its secretion is upregulated (40). Usually, elevated HPA expression during inflammation has been reported to be associated with several mechanisms, including HS degradation, ECM remodeling, increased inflammatory cell migration to the site of injury, and the release of chemokines anchored to the cell surface and ECM (41).

A classic example of inflammatory disease is inflammatory bowel disease (IBD), which is a chronic disease of the gastrointestinal tract that is caused by inappropriate mucosal immune responses. It has a variety of causes, including genetic alterations, intestinal epithelial defects and altered intestinal luminal flora composition $(3,42)$. Ulcerative colitis (UC) and Crohn's disease (CD), which are the two main forms of IBD, are incurable and have a high incidence rate among young individuals (43). UC is a severe ulcerative inflammatory disease that is limited to the colon and rectum, extending 
only to the mucosa and submucosa (3). By contrast, $\mathrm{CD}$, also known as regional enteritis due to frequent ileal involvement, may involve any region of the gastrointestinal tract and usually affects the bowel wall through to the muscular layer (3).

In patients with IBD, the balance between the immune response of the pathogen and the tolerance of normal flora is disrupted, resulting in the uncontrolled absorption of pro-inflammatory substances (bacteria and bacterial products) in the intestinal tract. This activates the immune system, thus releasing cytokines and ultimately leading to structural and functional dysfunction of the epithelial barrier $(3,44)$. In addition, due to the importance of HS in maintaining the integrity of the intestinal wall $(4,45)$, the enzymatic degradation of HS is considered to markedly affect the permeability and inflammatory response of the colon.

Therefore, the effect of HPA on HS impacts numerous aspects of inflammation, and the role of HPA is crucial during the initial stages and progression of inflammation.

\section{HPA in gastrointestinal dysfunction}

In addition to IBD, the roles of HPA in other gastrointestinal disorders have also been reported. In colitis, the enzymatic activity of HPA greatly enhances the activation of macrophages by lipopolysaccharide, leading to a significant increase in the expression of certain inflammatory factors, such as TNF- $\alpha$, IL-6 and IL-12, promoting the occurrence of inflammation (21). A previous study also demonstrated that intestinal barrier disruption occurred as a result of the excessive production of pro-inflammatory cytokines (TNF- $\alpha$, IL- $1 \beta$ and IFN- $\gamma$ ) (46). During the process of intestinal inflammation, the inflammatory effect of HPA therefore plays a key role in early stages.

Among the aforementioned inflammatory factors, TNF- $\alpha$ is a pro-inflammatory cytokine that stimulates increased IL-1 production, leukocyte migration, angiogenesis (47) and potentially the development of septic shock (5). TNF- $\alpha$ increases the levels of various MMPs, such as MMP9, MMP12 and MMP19, which disrupt the intestinal ECM (48). Furthermore, HPA expression in intestinal epithelial cells can be induced by activated macrophages, most likely through the TNF- $\alpha$-mediated stimulation of the transcription factor early growth response 1 , which is a powerful inducer of HPA transcription in colon cells $(21,49)$. Therefore, TNF- $\alpha$ plays an important role in inflammation and sepsis.

Chronic inflammation can promote the progression of tumors by mobilizing tumor-related immune cells to promote angiogenesis, cell invasion and metastasis (50). Therefore, chronic gastric inflammation and chronic intestinal inflammation may predispose individuals to gastric and colorectal cancer, respectively $(51,52)$. It is well known that the BM and ECM act as barriers to prevent tumor cell invasion and metastasis (23). Enzymatic hydrolysis of HPA disrupts this barrier function, and HPA is one of the key enzymes involved in the invasion and metastasis of malignant tumors (53). Furthermore, HPA overexpression has been observed to be significantly associated with reduced tumor survival (53). HPA is overexpressed in gastric cancer, and a previous in vitro study (54) revealed that gene silencing via HPA can effectively inhibit the proliferation, invasion, metastasis and angiogenesis of gastric cancer cells (54). Similarly, HPA is overexpressed in colon cancer, which is closely associated with chronic inflammatory pathways (21). HPA is also emerging as a new target for the treatment of tumors, and novel therapeutic approaches derived from HPA are currently being developed. Thus, HPA plays an important role in gastrointestinal dysfunction, whether it is induced by inflammation or tumors (Table I).

\section{HPA in sepsis}

Sepsis is one of the main causes of mortality among critically ill patients (55). Sepsis is now defined as life-threatening organ dysfunction caused by a dysfunctional response of the host to infection (56). Septic shock is part of sepsis and is accompanied by impaired circulatory and cellular metabolism, thus making it associated with a higher risk of mortality (56).

Despite advances in medicine, mortality due to septic shock remains high (35-40\%). The main causes of mortality include acute gastrointestinal injury (AGI), acute respiratory distress syndrome, acute kidney injury and multiple organ dysfunction syndrome (MODS) (56). Septic shock remains the leading cause of mortality among critically ill patients (56). Based on data from high-income countries, it has been estimated that there are $\sim 31.5$ million cases of sepsis worldwide, 19.4 million cases of severe sepsis worldwide and possibly $\leq 5.3$ million fatalities per year (57).

Sepsis is characterized by acute endothelial dysfunction, increased vascular permeability, the activation of clotting cascades and tissue edema, resulting in the compromised perfusion of vital organs (58). A previous study reported that an early event of sepsis can induce endothelial injury (59). Syndecan-1 is a biomarker of endothelial dysfunction. It is a transmembrane HS proteoglycan that is mainly expressed by intestinal epithelial cells, and is closely associated with the inflammatory process and the integrity of the intestinal mucosa (60). In addition, the highly sulphated and heterotopic form of HS is the main functional component of syndecan-1, which is structurally similar to HP $(60,61)$. Syndecan-1 levels are elevated during sepsis, which may be attributed to GAG shedding during endosaccharide calyx abscission. Furthermore, the plasma concentrations of syndecan-1 correlate with sequential organ failure assessment scores $(60,62)$.

A previous study revealed that the inflammatory activation of endothelial cells in sepsis is associated with calyx loss (62). Another study demonstrated that circulating GAGs were elevated in patients with septic shock and, importantly, that GAG levels were associated with mortality (63). The glycocalyx is composed of HS, other GAGs, proteoglycans and glycoproteins, and acts as a thin gel-like endothelial layer that covers the surface of vascular lumens, thus constituting a barrier to circulating cells and controlling the utilization of circulating leukocytes by adhesion molecules on the endothelial surface (64). In addition, it has been elucidated that unisolated HP (an inhibitor of HPA) reduces calyx loss in animal models of sepsis, which is possibly related to the inhibition of inflammatory factors (65), thereby controlling the progression of sepsis.

In conclusion, syndecan-1, calyx, GAGs and other substances are crucial for the integrity of the endothelial barrier and are structurally associated with HPA. The degradation of 
Table I. Role of HPA in various gastrointestinal diseases.

Author (year)

Role of HPA

(Refs.)

Lerner et al (2011)

HPA greatly enhanced the activation of lipopolysaccharide, promoting the

Bischoff et al (2014)

inflammatory response in colitis.

HPA stimulated the excessive production of pro-inflammatory cytokines in intestinal tissues.

Hermano et al (2012)

The transcription factor, early growth response 1 , induced the expression of HPA in intestinal epithelial cells.

Zheng et al (2010)

HPA promoted cell proliferation, invasion, metastasis and angiogenesis in gastric cancer.

Chen et al (2017) HPA aggravated intestinal injury in septic rats.

HPA, heparinase; Ref., reference.

these molecules leads to defects in the endothelial barrier and the aggravation of inflammation, which indicates that HPA is involved in the occurrence and development of sepsis.

A previous study revealed that HPA is closely associated with the occurrence and development of sepsis (66). HPA expression was increased in animal models of septic lung and kidney injury, suggesting that HPA may be involved in the early onset of sepsis (66). An additional study demonstrated that expression of the gene coding for HPA (hepP) plays an important role in a mouse model of sepsis induced by Pseudomonas aeruginosa, and that mutations in the hepP gene enhance survival in infected mice (67-69). A previous in vivo study determined that patients with sepsis induced by gram-negative bacteria exhibited a pronounced increase in plasma HPA activity (70). It has also been clinically reported that HP can reduce the mortality of patients with sepsis and septic shock (71). Although its anticoagulant effect has been demonstrated, HP may also play an antagonistic role against HPA (71). The results of these studies suggest that the expression of HPA accelerates the progression of sepsis, and that HPA inhibitors may serve to treat sepsis.

Overall, HPA plays an important role in sepsis and inflammation, contributes to the process of sepsis and is likely to be involved in the early process of sepsis. Thus, it was speculated that HPA may be a diagnostic indicator of early sepsis and that HPA inhibitors may serve as a form of targeted therapy.

\section{HPA in the gastrointestinal dysfunction of sepsis}

For decades, the gastrointestinal tract has been considered to be the driving force behind sepsis and MODS (46). The intestinal tract is one of the most metabolically active systems in the human body. It must constantly balance the entry of molecules such as water, electrolytes and nutrients, while also maintaining the presence of antigens in the inflammatory environment (46). A complete intestinal barrier is therefore essential to the health of an individual. In addition, the gastrointestinal barrier can prevent the invasion and transfer of bacteria in the lumen without overreacting to symbiotic microorganisms (72), which is important, as an excessive response could easily lead to gastrointestinal dysfunction and a range of diseases.
In sepsis, the gastrointestinal tract is the first and most likely organ to be involved. Gastrointestinal dysfunction often occurs in patients with sepsis, and sepsis has been reported to cause AGI in $>90 \%$ of patients (73). AGI causes intestinal bacteria translocation, endotoxin translocation and enterogenous infection, which can lead to the occurrence or aggravation of sepsis, and even septic shock and MODS (74). In addition, previous studies have reported that the AGI grading scheme is closely associated with the prognosis of patients with severe illness, and can be used to determine the severity of gastrointestinal dysfunction while serving as a robust predictor of mortality $(75,76)$. Therefore, AGI is considered to represent an initial stage of sepsis; however, the diagnosis of AGI in sepsis is limited to clinical symptoms as there is still a lack of effective biomarkers (77). Furthermore, the effects of traditional treatments for the AGI of sepsis are suboptimal. Therefore, protecting the gastrointestinal tract is a key goal for the prevention and treatment of sepsis (77). Thus, it is necessary to identify biomarkers and effective intervention measures for the AGI of sepsis.

Although HPA was found to aggravate intestinal damage in septic rats, HPA inhibitors were revealed to reduce intestinal damage and inflammation (6) (Table I). In conclusion, HPA is likely to aggravate gastrointestinal dysfunction in sepsis, but the mechanism involved has yet to be determined. The current study hypothesized that this mechanism may be related to autophagy, exosomes and certain signaling pathways, which should be investigated in further studies.

\section{Summary and perspective}

Due to the increasing number of studies on HPA, its role in medicine is being explored and its application is expanding. The present review summarized the role of HPA in the enzymatic and non-enzymatic activity of HP, which destroys the cell barrier and leads to the enhancement of the inflammatory response (which, in severe cases, may result in systemic inflammatory response) (23). HPA may also aggravate sepsis and the progress of gastrointestinal dysfunction; thus, it was inferred that HPA aggravates gastrointestinal dysfunction in sepsis. The mechanisms involved are likely associated with autophagy, exosomes and certain signaling pathways; however, 
these assumptions require further elucidation. In future, HPA may be able to predict the early occurrence of sepsis and may serve as a biomarker, while HPA inhibitors may become novel target drugs for the treatment of gastrointestinal dysfunction in sepsis that are capable of reducing the mortality rate of this disease.

\section{Acknowledgements}

Not applicable.

\section{Funding}

The present study was funded by the Science and Technology Department of Gansu Province (grant no. 20JR5RA35); the Talent Innovation and Entrepreneurship Project of Science and Technology, Bureau of Chengguan District, Lanzhou (grant no. 2020RCCX0030); Lanzhou Science and Technology Development Guiding Plan Project (grant no. 2019-ZD-37); the Fund of The First Hospital of Lanzhou University (grant no. Ldyyyn2018-48); the Fund of Donggang Branch, The First Hospital of Lanzhou University (grant no. ldyydgyn-201705); and The Open Topics of the Key Laboratory of Biological Treatment and Regenerative Medicine in Gansu Province (grant no. zdsyskfkt-201702).

\section{Availability of data and materials}

Not applicable.

\section{Authors' contributions}

LPL conceived the current study. TTC designed and wrote the manuscript. JJL analyzed the feasibility of the article and searched the literature. LC and YWG searched the literature and revised the article. Data authentication is not applicable. All the authors have read and approved the final version of the manuscript.

\section{Ethics approval and consent to participate}

Not applicable.

\section{Patient consent for publication}

Not applicable.

\section{Competing interests}

The authors declare that they have no competing interests.

\section{References}

1. Tripathi CK, Banga J and Mishra V: Microbial heparin/Heparan Sulphate lyases: Potential and applications. Appl Microbiol Biotechno 94: 307-321, 2012.

2. Ma Q, Dudas B, Hejna M, Cornelli U, Lee JM, Lorens S, Mervis R, Hanin I and Fareed J: The blood-brain barrier accessibility of a heparin-derived oligosaccharides C3. Thromb Res 105: 447-453, 2002.

3. Xavier RJ and Podolsky DK: Unravelling the pathogenesis of inflammatory bowel disease. Nature 448: 427-434, 2007.
4. Belmiro CL, Souza HS, Elia CC, Castelo-Branco MT, Silva FR, Machado RL and Pavão MS: Biochemical and immunohistochemical analysis of glycosaminoglycans in inflamed and non-inflamed intestinal mucosa of patients with Crohn's disease. Int J Colorectal Dis 20: 295-304, 2005.

5. Tracey KJ, Fong Y, Hesse DG, Manogue KR, Lee AT, Kuo GC, Lowry SF and Cerami A: Anti-cachectin/TNF monoclonal antibodies prevent septic shock during lethal bacteraemia. Nature 330: 662-664, 1987.

6. Chen S, He Y, Hu Z, Lu S, Yin X, Ma X, Lv C and Jin G: Heparanase mediates intestinal inflammation and injury in a mouse model of sepsis. J Histochem Cytochem 65: 241-249, 2017.

7. Fu L, Zhang F, Li G, Onishi A, Bhaskar U, Sun P and Linhardt RJ: Structure and activity of a new low-molecular-weight heparin produced by enzymatic ultrafiltration. J Pharm Sci 103: 1375-1383, 2014.

8. Weiss RJ, Esko JD and Tor Y: Targeting heparin and heparan sulfate protein interactions. Org Biomol Chem 15: 5656-5668, 2017.

9. Kandrotas RJ: Heparin pharmacokinetics and pharmacodynamics. Clin Pharmacokinet 22: 359-374, 1992.

10. Castelli R, Porro F and Tarsia P: The heparins and cancer: Review of clinical trials and biological properties. Vasc Med 9: 205-213, 2004

11. Casu B, Guerrini M and Torri G: Structural and conformational aspects of the anticoagulant and anti-thrombotic activity of heparin and dermatan sulfate. Curr Pharm Des 10: 939-949, 2004.

12. Pike RN, Buckle AM, le Bonniec BF and Church FC: Control of the coagulation system by serpins. Getting by with a little help from glycosaminoglycans. FEBS J 272: 4842-4851, 2005.

13. Walenga JM and Lyman GH: Evolution of heparin anticoagulants to ultra-low-molecular-weight heparins: A review of pharmacologic and clinical differences and applications in patients with cancer. Crit Rev Oncol Hematol 88: 1-18, 2013.

14. Li X, Liu Z, Luo M, Xi Y, Li C, Wang S and Yang R: Therapeutic effect of low-molecular-weight heparin on adult sepsis: A metaanalysis. Ann Palliat Med.Mar 10: 3115-3127, 2021.

15. Vlodavsky I, Friedmann Y, Elkin M, Aingorn H, Atzmon R, Ishai-Michaeli R, Bitan M, Pappo O, Peretz T, Michal I, et al: Mammalian heparanase: Gene cloning, expression and function in tumor progression and metastasis. Nat Med 5: 793-802, 1999.

16. McKenzie E, Tyson K, Stamps A, Smith P, Turner P, Barry R, Hircock M, Patel S, Barry E, Stubberfield C, et al: Cloning and expression profiling of $\mathrm{Hpa} 2$, a novel mammalian heparanase family member. Biochem Biophys Res Commun 276: 1170-1177, 2000.

17. Yingying X, Yong Z, Zhenning W, Xue Z, Li J, Yang L and Huimian X: Role of heparanase-1 in gastric carcinoma invasion. Asian Pac J Cancer Prev 10: 151-154, 2009.

18. Meirovitz A, Hermano E, Lerner I, Zcharia E, Pisano C, Peretz T and Elkin M: Role of heparanase in radiation-enhanced invasiveness of pancreatic carcinoma. Cancer Res 71: 2772-2780, 2011.

19. Shafat I, Pode D, Peretz T, Ilan N, Vlodavsky I and Nisman B: Clinical significance of urine heparanase in bladder cancer progression. Neoplasia 10: 125-130, 2008.

20. Boyango I, Barash U, Naroditsky I, Li JP, Hammond E, Ilan N and Vlodavsky I: Heparanase cooperates with Ras to drive breast and skin tumorigenesis. Cancer Res 74: 4504-4514, 2014.

21. Lerner I, Hermano E, Zcharia E, Rodkin D, Bulvik R, Doviner V, Rubinstein AM, Ishai-Michaeli R, Atzmon R, Sherman Y, et al: Heparanase powers a chronic inflammatory circuit that promotes colitis-associated tumorigenesis in mice. J Clin Invest 121: 1709-1721, 2011.

22. Akbarshahi H, Axelsson JB, Said K, Malmström A, Fischer H and Andersson R: TLR4 dependent heparan sulphate-induced pancreatic inflammatory response is IRF3-mediated. J Transl Med 9: 219, 2011.

23. Fernandes CL, Escouto GB and Verli H: Structural glycobiology of heparinase II from Pedobacter heparinus. J Biomol Struct Dyn 32: 1092-1102, 2013.

24. Häcker U, Nybakken K and Perrimon N: Heparan sulphate proteoglycans: The sweet side of development. Nat Rev Mol Cell Biol 6: 530-541, 2005.

25. Fux L, Ilan N, Sanderson RD and Vlodavsky I: Heparanase: Busy at the cell surface. Trends Biochem Sci 34: 511-519, 2009.

26. Rivara S, Milazzo FM and Giannini G: Heparanase: A rainbow pharmacological target associated to multiple pathologies including rare diseases. Future Med Chem 8: 647-680, 2016. 
27. Levy-Adam F, Feld S, Suss-Toby E, Vlodavsky I and Ilan N: Heparanase facilitates cell adhesion and spreading by clustering of cell surface heparan sulfate proteoglycans. PLoS One 3: e2319, 2008

28. Bass MD, Roach KA, Morgan MR, Mostafavi-Pour Z Schoen T, Muramatsu T, Mayer U, Ballestrem C, Spatz JP and Humphries MJ: Syndecan-4-dependent Rac1 regulation determines directional migration in response to the extracellular matrix. J Cell Biol 177: 527-538, 2007.

29. Dovas A, Yoneda A and Couchman JR: PKCbeta-dependent activation of RhoA by syndecan-4 during focal adhesion formation. J Cell Sci 119: 2837-2846, 2006.

30. Tkachenko E, Elfenbein A, Tirziu D and Simons M: Syndecan-4 clustering induces cell migration in a PDZ-dependent manner. Circ Res 98: 1398-1404, 2006.

31. Zhang X, Han X, Xia K, Xu Y, Yang Y, Oshima K, Haeger SM, Perez MJ, McMurtry SA, Hippensteel JA, et al: Circulating heparin oligosaccharides rapidly target the hippocampus in sepsis, potentially impacting cognitive functions. Proc Natl Acad Sci USA 116: 9208-9213, 2019.

32. Ruan J, Trotter TN, Nan L, Luo R, Javed A, Sanderson RD, Suva LJ and Yang Y: Heparanase inhibits osteoblastogenesis and shifts bone marrow progenitor cell fate in myeloma bone disease. Bone 57: 10-17, 2013

33. Smith PN, Freeman C, Yu D, Chen M, Gatenby PA, Parish CR and Li RW: Heparanase in primary human osteoblasts. J Orthop Res 28: 1315-1322, 2010.

34. Thompson CA, Purushothaman A, Ramani VC, Vlodavsky I and Sanderson RD: Heparanase regulates secretion, composition, and function of tumor cell-derived exosomes. J Biol Chem 288 : 10093-10099, 2013.

35. Shteingauz A, Boyango I, Naroditsky I, Hammond E, Gruber M, Doweck I, Ilan N and Vlodavsky I: Heparanase enhances tumor growth and chemoresistance by promoting autophagy. Cancer Res 75: 3946-3957, 2015

36. Dunlop EA and Tee AR: mTOR and autophagy: A dynamic relationship governed by nutrients and energy. Semin Cell Dev Biol 36: 121-129, 2014.

37. Qiu P, Liu Y and Zhang J: Review: The role and mechanisms of macrophage autophagy in sepsis. Inflammation 42: 6-19, 2019.

38. Vlodavsky I, Eldor A, Haimovitz-Friedman A, Matzner Y, Ishai-Michaeli R, Lider O, Naparstek Y, Cohen IR and Fuks Z: Expression of heparanase by platelets and circulating cells of the immune system: Possible involvement in diapedesis and extravasation. Invasion Metastasis 12: 112-127, 1992.

39. Young E: The anti-inflammatory effects of heparin and related compounds. Thromb Res 122: 743-752, 2007.

40. Ilan N, Elkin M and Vlodavsky I: Regulation, function and clinical significance of heparanase in cancer metastasis and angiogenesis. Int J Biochem Cell Biol 38: 2018-2039, 2006

41. Li JP and Vlodavsky I: Heparin, heparan sulfate and heparanase in inflammatory reactions. Thromb Haemost 102: 823-828, 2009.

42. Flynn S and Eisenstein S: Inflammatory bowel disease presentation and diagnosis. Surg Clin North Am 99: 1051-1062, 2019.

43. Dias AM, Correia A, Pereira MS, Almeida CR, Alves I, Pinto V, Catarino TA, Mendes N,Leander M, Oliva-Teles MT, et al: Metabolic control of T cell immune response through glycans in inflammatory bowel disease. Proc Natl Acad Sci USA 115: E4651-E4660, 2018.

44. Clayburgh DR, Shen L and Turner JR: A porous defense: The leaky epithelial barrier in intestinal disease. Lab Invest 84 282-291, 2004

45. Bode L, Salvestrini C, Park PW, Li JP, Esko JD, Yamaguchi Y, Murch S and Freeze HH: Heparan sulfate and syndecan-1 are essential in maintaining murine and human intestinal epithelial barrier function. J Clin Invest 118: 229-238, 2008.

46. Bischoff SC, Barbara G, Buurman W, Ockhuizen T, Schulzke JD, Serino M, Tilg H, Watson A and Wells JM: Intestinal permeability-a new target for disease prevention and therapy. BMC Gastroenterol 14: 189, 2014.

47. Baud V and Karin M: Signal transduction by tumor necrosis factor and its relatives. Trends Cell Biol 11: 372-377, 2001.

48. Pender SL, Braegger C, Gunther U, Monteleone G, Meuli M, Schuppan D and Macdonald TT: Matrix metalloproteinases in necrotising enterocolitis. Pediatr Res 54: 160-164, 2003.

49. Hermano E, Lerner I and Elkin M: Heparanase enzyme in chronic inflammatory bowel disease and colon cancer. Cell Mol Life Sci 69: 2501-2513, 2012.

50. Hanahan D and Weinberg RA: Hallmarks of cancer: The next generation. Cell 144: 646-674, 2011
51. Chiba T, Marusawa $\mathrm{H}$ and Ushijima T: Inflammation-associated cancer development in digestive organs: Mechanisms and roles for genetic and epigenetic modulation. Gastroenterology 143: $550-563,2012$

52. Gupta RB, Harpaz N, Itzkowitz S, Hossain S, Matula S, Kornbluth A, Bodian C and Ullman T: Histologic inflammation is a risk factor for progression to colorectal neoplasia in ulcerative colitis: A cohort study. Gastroenterology 133: 1099-1105, 2007.

53. Vlodavsky I, Ilan N, Nadir Y, Brenner B, Katz BZ, Naggi A, Torri G, Casu B and Sasisekharan R: Heparanase, heparin and the coagulation system in cancer progression. Thromb Res 120 (Suppl 2): S112-S120, 2007.

54. Zheng L, Jiang G, Mei H, Pu J, Dong J, Hou X and Tong Q: Small RNA interference-mediated gene silencing of heparanase abolishes the invasion, metastasis and angiogenesis of gastric cancer cells. BMC Cancer 10: 33, 2010.

55. Levy MM, Fink MP, Marshall JC, Abraham E, Angus D, Cook D, Cohen J, Opal SM, Vincent JL and Ramsay G; SCCM/ ESICM/ACCP/ATS/SIS: 2001 SCCM/ESICM/ACCP/ATS/SIS International sepsis definitions conference. Crit Care Med 31: 1250-1256, 2003

56. Shankar-Hari M, Phillips GS, Levy ML, Seymour CW, Liu VX, Deutschman CS, Angus DC, Rubenfeld GD and Singer M; Sepsis Definitions Task Force: Developing a new definition and assessing new clinical criteria for septic shock: For the third international consensus definitions for sepsis and septic shock (Sepsis-3). JAMA 315: 775-787, 2016.

57. Vincent JL, Jones G, David S, Olariu E and Cadwell KK: Frequency and mortality of septic shock in Europe and North America: A systematic review and meta-analysis. Crit Care 23: 196, 2019

58. Bermejo-Martin JF, Martín-Fernandez M, López-Mestanza C, Duque P and Almansa R: Shared features of endothelial dysfunction between sepsis and its preceding risk factors (Aging and Chronic Disease). J Clin Med 7: 400, 2018.

59. Martin-Fernandez M, Vaquero-Roncero LM, Almansa R, Gómez-Sánchez E, Martín S, Tamayo E, Esteban-Velasco MC, Ruiz-Granado P, Aragón M, Calvo D, et al: Endothelial dysfunction is an early indicator of sepsis and neutrophil degranulation of septic shock in surgical patients. BJS Open 4: 524-534, 2020.

60. Floer M, Götte M, Wild MK, Heidemann J, Gassar ES Domschke W, Kiesel L,Luegering A and Kucharzik T: Enoxaparin improves the course of dextran sodium sulfate-induced colitis in syndecan-1-deficient mice. Am J Pathol 176: 146-157, 2009.

61. Yan Y, Ji Y, Su N, Mei X, Wang Y, Du S, Zhu W, Zhang C, $\mathrm{Lu} \mathrm{Y}$ and Xing XH: Non-anticoagulant effects of low molecular weight heparins in inflammatory disorders: A review. Carbohydr Polym 160: 71-81, 2017

62. Sallisalmi M, Tenhunen J, Yang R, Oksala N and Pettilä V: Vascular adhesion protein-1 and syndecan-1 in septic shock. Acta Anaesthesiol Scand 56: 316-322, 2012

63. Nelson A, Berkestedt I, Schmidtchen A, Ljunggren L and Bodelsson M: Increased levels of glycosaminoglycans during septic shock: Relation to mortality and the antibacterial actions of plasma. Shock 30: 623-627, 2008.

64. Weinbaum S, Tarbell JM and Damiano ER: The structure and function of the endothelial glycocalyx layer. Annu Rev Biomed Eng 9: 121-167, 2007.

65. Yini S, Heng Z, Xin A and Xiaochun M: Effect of unfractionated heparin on endothelial glycocalyx in a septic shock model. Acta Anaesthesiol Scand 59: 160-169, 2015.

66. Schmidt EP, Yang Y, Janssen WJ, Gandjeva A, Perez MJ, Barthel L, Zemans RL, Bowman JC, Koyanagi DE, Yunt ZX, et al: The pulmonary endothelial glycocalyx regulates neutrophil adhesion and lung injury during experimental sepsis. Nat Med 18: 1217-1223, 2012

67. Obritsch MD, Fish DN, MacLaren R and Jung R: Nosocomial infections due to multidrug-resistant Pseudomonas aeruginosa: Epidemiology and treatment options. Pharmacotherapy 25: 1353-1364, 2005

68. Dzvova N, Colmer-Hamood JA, Griswold JA and Hamood AN: Heparinase is essential for Pseudomonas aeruginosa virulence during thermal injury and infection. Infect Immun 86: e00755-e00817, 2017.

69. Dzvova N, Colmer-Hamood JA, Griswold JA and Hamood AN: Isolation and characterization of HepP: A virulence-related Pseudomonas aeruginosa heparinase. BMC Microbiol 17: 233, 2017. 
70. Martin L, De Santis R, Koczera P, Simons N, Haase H, Heinbockel L, Brandenburg K, Marx G and Schuerholz T: The synthetic antimicrobial peptide 19-2.5 interacts with heparanase and heparan sulfate in murine and human sepsis. PLoS One 10: e0143583, 2015.

71. Zarychanski R, Abou-Setta AM, Kanji S, Turgeon AF, Kumar A, Houston DS, Rimmer E, Houston BL, McIntyre L, Fox-Robichaud AE, et al: The efficacy and safety of heparin in patients with sepsis: A systematic review and metaanalysis. Crit Care Med 43: 511-518, 2015.

72. Cho SX, Berger PJ, Nold-Petry CA and Nold MF: The immunological landscape in necrotising enterocolitis. Expert Rev Mol Med 18: e12, 2016

73. Reintam Blaser A, Malbrain ML, Starkopf J, Fruhwald S, Jakob SM, De Waele J, Braun JP, Poeze M and Spies C: Gastrointestinal function in intensive care patients: Terminology, definitions and management. Recommendations of the ESICM Working Group on Abdominal Problems. Intensive Care Med 38 384-394, 2012

74. Chen H, Zhang H, Li W, Wu S and Wang W: Acute gastrointestinal injury in the intensive care unit: A retrospective study. Ther Clin Risk Manag 11: 1523-1529, 2015.
75. Hu B, Sun R, Wu A, Ni Y, Liu J, Guo F, Ying L, Ge G, Ding A, Shi Y, et al: Severity of acute gastrointestinal injury grade is a predictor of all-cause mortality in critically ill patients: A multicenter, prospective, observational study. Crit Care 21: 188, 2017.

76. Reintam A, Parm P, Kitus R, Starkopf J and Kern H: Gastrointestinal failure score in critically ill patients: A prospective observational study. Crit Care 12: R90, 2008.

77. Fleischmann C, Scherag A, Adhikari NK, Hartog CS, Tsaganos T, Schlattmann P, Angus DC and Reinhart K; International Forum of Acute Care Trialists: Assessment of global incidence and mortality of hospital-treated sepsis. Current estimates and limitations. Am J Respir Crit Care Med 193: 259-272, 2016.

This work is licensed under a Creative Commons Attribution-NonCommercial-NoDerivatives 4.0 International (CC BY-NC-ND 4.0) License. 